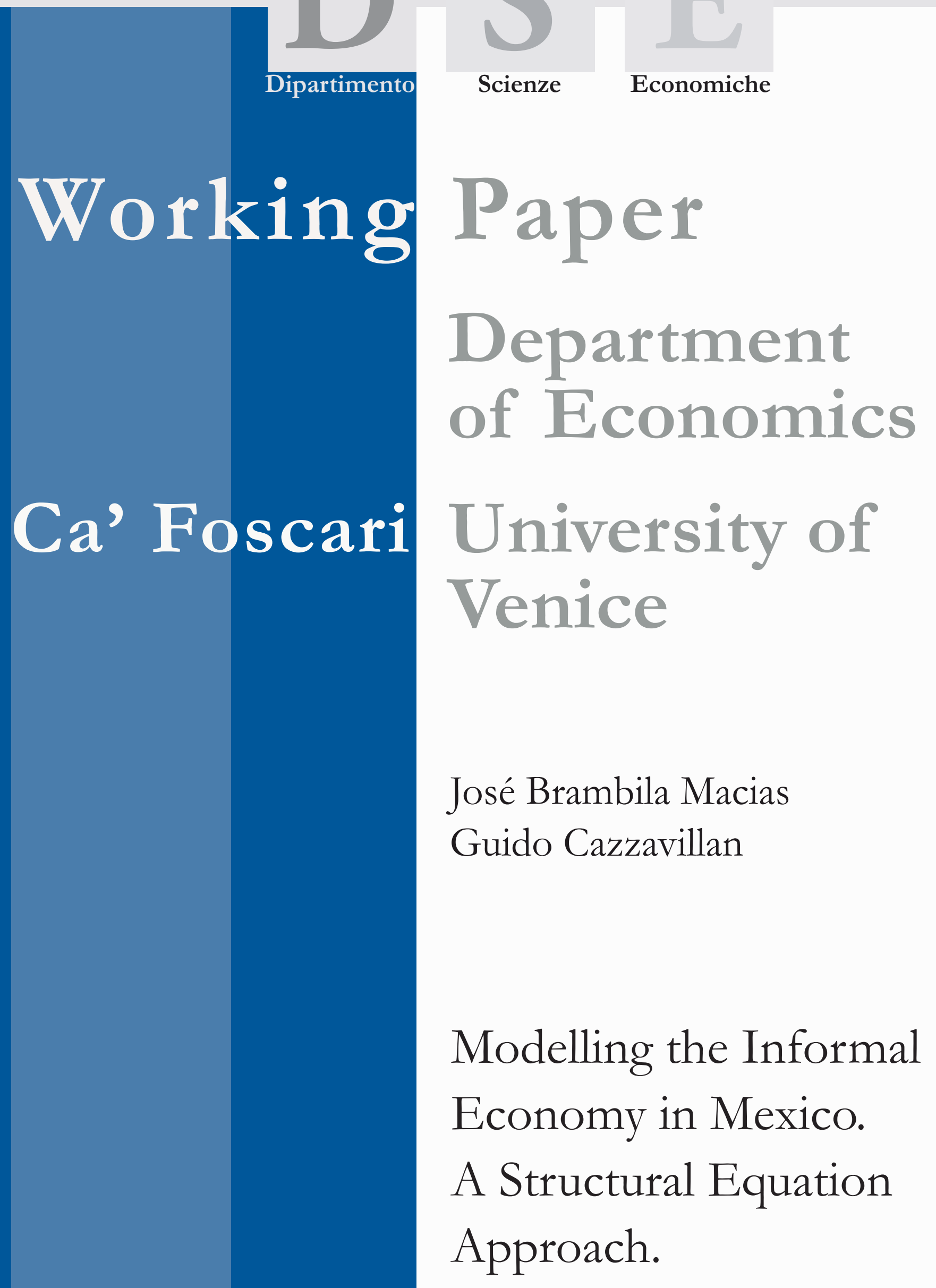




\title{
Modelling the Informal Economy in Mexico. A Structural Equation Approach
}

\author{
José Brambila Macias \\ Trade and Markets Division Fao-UN \\ Guido Cazzavillan \\ Department of Economics \\ Ca'Foscari University of Venice
}

First Draft: 18/11/2008

\begin{abstract}
This paper uses annual data for the period 1970-2006 in order to estimate and investigate the evolution of the Mexican informal economy. In order to do so, we model the informal economy as a latent variable and try to explain it through relationships between possible cause and indicator variables using structural equation modeling (SEM). The model uses tax burden, salary levels, inflation, unemployment and excessive regulation as potential incentives or deterrents for the informal economy. Our results indicate that the Mexican informal sector at the beginning of the 1970's accounted for 40 percent of GDP, and then it slightly decreased to stabilize around 30 percent of GDP from the late 1980's onwards. The results also confirm the importance of salaries and excessive regulation as causes of the informal economy in Mexico and the existence of a positive relationship between informality and GDP.
\end{abstract}

\section{Keywords}

Informal Economy, Economic Growth, Structural Equations.

\section{JEL Codes}

C39, E27, O17.

\author{
Address for correspondence: \\ Guido Cazzavillan \\ Department of Economics \\ Ca' Foscari University of Venice \\ Cannaregio 873, Fondamenta S.Giobbe \\ 30121 Venezia - Italy \\ Phone: $(++39) 0412349152$ \\ Fax: (++39) 0412349176 \\ e-mail: guido@unive.it
}

This Working Paper is published under the auspices of the Department of Economics of the Ca' Foscari University of Venice. Opinions expressed herein are those of the authors and not those of the Department. The Working Paper series is designed to divulge preliminary or incomplete work, circulated to favour discussion and comments. Citation of this paper should consider its provisional character. 


\section{Introduction}

Informality has re-gained economists' attention in the past years due to a generalized perception that the informal sector around the globe is expanding. Understanding the causes of informality and the impact it might have on the economy, especially on growth, is fundamental to develop effective policy measures and to avoid its potential negative externalities.

The term "Informal Economy" was coined by Hart $(1973 ; 1990)$, who used this term to explain certain self-employment characteristics in Africa. Nowadays, the concept of informality has evolved and encompasses a broad set of economic activities, which can go from street vendors to hidden production, illegal labour, corruption, smuggling, prostitution and tax avoidance. This phenomenon affetcs both developing and rich countries alike.

In the literature, the informal sector is refered as black market, shadow economy, illegal economy, corruption, not registered economy, underground economy, informal economy, and so on. Sometimes these definitions are used as synonyms; however, in some occasions they differ in meaning depending on which particular dimension of informality they focus (i.e. tax avoidance, corruption, illegal labour, etc.). Nevertheless, all these definitions refer to unregistered or unreported activities within the economy.

Given the unregistered (hidden) nature of informal activities, measuring or estimating the actual size of informality is very difficult. Through the years a wide range of methods ${ }^{2}$ and techniques have been used, although none of them is fully recognized or totally reliable.

In Mexico, as well as in the rest of the Latin America, the phenomenon of informality is clearly visible on the streets of the major cities ${ }^{3}$. The so called "street vendors" (vendedores ambulantes) plague huge areas of the Latin American capitals, obstructing entire streets and generating unfair competition to the official establishment. These informal agents manage to operate outside the formal framework and are a constant source of externalities to the economy. Although most economists would agree with this, the magnitude and sign of these externalities are still unclear and open to debate. This is in part due to the lack of consensus among researchers regarding a common definition and a robust estimation technique able to capture all the dimensions of the informal sector.

From a policy perspective, in particular for a developing country like Mexico, measuring and understanding the evolution of the informal sector becomes imperative, especially when its magnitude is believed to be relatively high. In fact, the International Labor Organization (1999), Schneider (2002), and Vuletin (2006) estimate that the size of the Mexican informal sector in the past decade ranged from 30 to 40 percent of GDP employing more or less the same percentage of the available labor force ${ }^{4}$. So, identifying the main causes of informality and the channels through which it interacts and affects the Mexican economy is the main objective of this paper.

\footnotetext{
${ }^{1}$ See Schneider and Enste (2000).

2 Garcia-Verdu (2007) gives a comprehensive description of the available methodologies to estimate the size of the informal sector. ${ }^{3}$ We refer interest readers to an excellent book by Roubaud (1995) on which the author analyzes in deep the roots and
potential causas of Informality in Mexico.

${ }^{4}$ See INEGI surveys on informal employment in the Appendix.
} 
Prior to discussing the different methodologies available for the estimation of the informal sector, we shall pin down a basic definition. Below we present the International Labor Organization (ILO) official definition for the informal sector:

"The informal sector is broadly characterized as consisting of units engaged in the production of goods or services with the primary objective of generating employment and incomes to the persons concerned.

These units typically operate at a low level of organisation, with little or no division between labour and capital as factors of production and on a small scale. Labour relations - where they exist - are based mostly on casual employment, kinship or personal and social relations rather than contractual arrangements with formal guarantees."

Source: International Labour Organization (ILO) Resolutions Concerning Statistics of Employment in the Informal Sector Adopted by the 15th International Conference of Labour Statisticians, January 1993, para. 5 .

Departing from the above definition, from now on, the informal sector in the present study will be treated as

"all the income and employment generating activities that are not regulated by the formal economic framework of a specific country".

It is important to point out that ILO's definition does not pronounce any judgement on whether the informal sector activities are good or bad for the economy. Indeed, the empirical literature has found mixed evidence in this regard ${ }^{5}$. So, understanding the effects and interactions between the Mexican informal sector and economic growth acquires high relevance for future policy frameworks .

In order to analyze the possible effects of informality, we need to estimate its magnitude and variation through time. To do so, we intend to use a structural equation approach, the so called Multiple Indicators Multiple Causes (MIMIC) model.

The rest of the paper is organized as follows. First, in Section 2, we give a brief description of the available measuring methods for the informal economy. In Section 3, we explain in deep the MIMIC model, emphasising its strengths and critics. Then, Section 4 summarizes the data and sources used in our MIMIC estimation. In Section 5 we report our results and, finally, in Section 6 we model the informal economy. Section 7 concludes and presents our final considerations as well as possible policy implications.

\section{Measuring Methods ${ }^{6}$}

As we explained above, informality per se has to do with hidden activities, but above all unregistered transactions. These transactions use mainly cash to reduce the risk of been detected or traced. So, measuring this type of elusive phenomena poses serious technical and methodological obstacles. Nevertheless, efforts have been made on developing ad hoc methodologies capable of tracking the dynamics of the informal economy.

\footnotetext{
${ }^{5}$ A detailed discussion on this point will take place in the following sections.

${ }^{6}$ We refer interested readers to the OECD handbook (2002), a joint publication with the IMF, ILO and CIS STAT.
} 
Garcia-Verdu (2007) classifies the methodologies available in the literature into three branches: Direct Methods, Indirect Methods, and the so called Model Approach.

1) Direct Methods: These methods refer to government surveys or tax audits and are the only ones officially accepted, although this does not mean that they are reliable sources, since informal agents are not necessarily incentivated to cooperate reporting the truth in this type of surveys. So, as usual, the real value may be above the survey results. In the Mexican case, the National Statistics Institute $\left(\mathrm{INEGI}^{7}\right)$ in cooperation with the Secretary for Labor and Social Prevension $\left(\mathrm{STPS}^{8}\right)$ carries out regular surveys on the so called microbusinesses (firms comprising a maximum of 15 persons) in an attempt to capture the size of informality. These surveys are called ENAMIN ${ }^{9}$ and include businesses working in industrial production, commerce, services and transports, as well as selfemployed persons.

2) Indirect Methods: Indirect methods use proxies in an attempt to capture the real size of the informal economy and can be sub-classified as follows:

a) Discrepancy Methods: These types of methods rely on differences between aggregate income and expenditure, or labor force and formal employment.

b) Monetary Methods: These methods are by far the most used in the empirical literature. They are based on the assumption that hidden transactions use only cash; so, estimating the quantity of money in circulation and then taking away the incentives that induce agents into informality (usually taxes) should give a good approximation for the money used in informal activities. Pioneer work using monetary approaches can be tracked back to Feige (1979) and Tanzi (1983).

c) Physical Input Methods: Input methods use discrepancies in electricity consumption and GDP. These methods were used mainly in former Soviet Union countries and extensive work can be found in Kaufmann and Kaliberda (1996).

3) Model Approach: This model uses structural equations to link unobserved variables to observed indicators and causes. The main model used to estimate the size of the informal economy is the so called Multiple Indicators Multiple Causes Model (MIMIC) and has gradually become the preferred method by researchers in the past years. Schneider (2002) among others helped to boost the use of the MIMIC approach within the academic community. A detailed description of this model will be given in the next section.

\section{The MIMIC Model}

\footnotetext{
${ }^{7}$ INEGI- Instituo Nacional de Estadistica, Geografia e Informatica.

${ }^{8}$ STPS- Secretaria del Trabajo y Prevision Social.

${ }^{9}$ ENAMIN- Encuesta Nacional de Micronegocios.
} 
Structural equation modeling (SEM) captures the relationships between latent unobserved variables and observed indicators and causes. This type of modeling has been used extensively in almost all social sciences, from sociology to marketing and economics. In economics one of the first researchers to apply the SEM was Goldberg (1972). In this paper, we will use one particular case of SEM, i.e. the Multiple Indicators and Multiple Causes Model (MIMIC) ${ }^{10}$. Frey and WeckHannemann (1984) were the first ones to apply the MIMIC to the estimation of the informal economy. On the Latin American scenario, Loayza (1997) and Vuletin (2006) developed the most representative studies using this method.

The MIMIC has two main components, a measurement equation and a structural equation.

The measurement equation corresponds to a set of observable indicators:

$$
Y_{1}=\lambda_{11} \eta+u_{1,} \quad Y_{2}=\lambda_{21} \eta+u_{2}, \Lambda, Y_{q}=\lambda_{q 1} \eta+u_{q}
$$

where, $Y_{1}, Y_{2}$ and $Y_{\mathrm{q}}$ represent the possible observable indicators of the informal economy (i.e. real GDP, currency held by the public or labor force participation ratio) and $\eta$ corresponds to the latent variable (in our case, the informal economy). Finally, $u$ is just a random error term and $\lambda$ stands for the structural parameters of the measurement model.

Next, we have the structural equation component:

$$
\eta=\gamma_{11} x_{1}+\gamma_{12} x_{2}+\gamma_{13} x_{3}+\Lambda+\gamma_{1 p} x_{p}+v
$$

with $x_{1}, x_{2}, x_{3}$ and $x_{\mathrm{p}}$ representing a set of observable causes, usually approximated by the tax burden (total tax revenue over GDP), unemployment, corruption, real salaries, inflation, confidence indexes, and so on. $\gamma_{11}, \gamma_{12}, \gamma_{13}$, and $\gamma_{1 p}$ are the structural parameters of the model and $v$ is the disturbance term. As in equation (1), in our model $\eta$ corresponds to the latent variable (informal economy).

Rewriting equations (1) and (2) we have:

$$
\begin{aligned}
& Y=\lambda n+u \\
& \eta=\gamma^{\prime} x+v
\end{aligned}
$$

where we are assuming independence between the errors and the disturbances, i.e. $E\left(u v^{\prime}\right)=\mathbf{0}$ ', and defining $E\left(v^{2}\right)=\sigma^{2}$ and $E\left(u u^{\prime}\right)=\Theta^{2}$, with $\Theta$ being the diagonal covariance matrix of the measurement errors.

So, in order to solve our model, we can substitute (4) into (3) to obtain a function of observable variables, that is:

$$
y=\lambda\left(\gamma^{\prime} x+v\right)+u
$$

Furthermore, defining $\Pi=\gamma \lambda$ ' and $\mathrm{w}=\lambda v+u$ we can rewrite (5) so that we can get the reduced form of our MIMIC model:

\footnotetext{
${ }^{10}$ Joreskog and Goldberg (1975) introduced for the first time the Multiple Indicators and Multiple Causes Model.
} 


$$
y=\Pi^{\prime} x+w
$$

Graphically, the MIMIC model can be represented as follows:

Figure 1. MIMIC Model

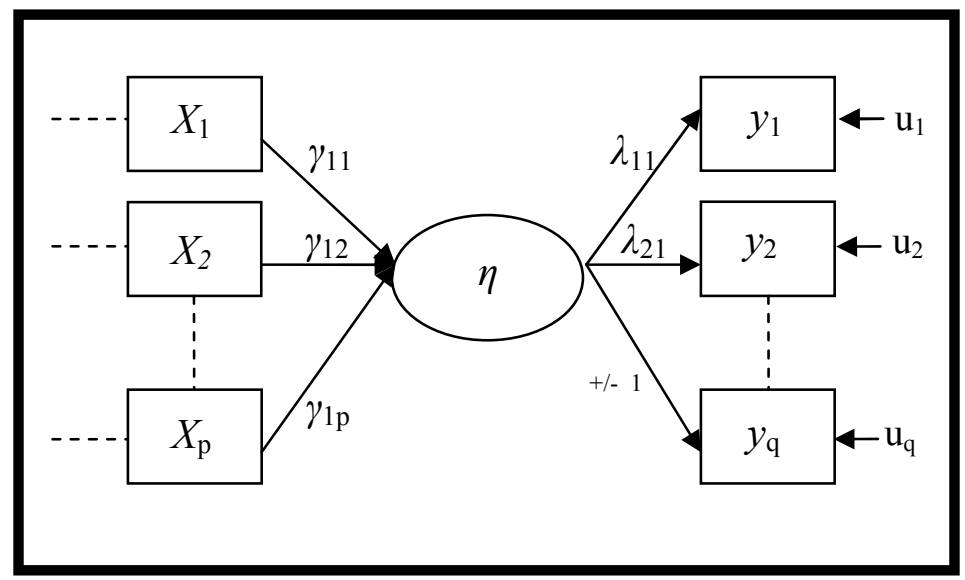

Analysing Figure 1, it is important to point out that, dealing with Structural Equation Models, a sufficient but not necessary condition of identification ${ }^{11}$ is that our MIMIC model should have at least one cause with at least two indicators. Furthermore, we need to assign a scale to our latent variable, $\eta$. Hence, as we can see from the above diagram, the parameter of the measurement model that corresponds to $y_{\mathrm{q}}$ is fixed to an exogenous value ${ }^{12}$, which can be +1 or -1 . The decision of which parameter should be fixed is up to the researcher and depends on the background economic theory being tested with the MIMIC model.

\section{Methodology and Data}

In order to estimate a series for the informal economy in Mexico, we use annual data starting in 1970 and ending in 2006. Most of the series used come from the IMF's International Financial Statistics as well as from the Mexican Central Bank (online) database. Not all the series were complete for the mentioned period, so missing data were extrapolated using various methods and alternative sources. A detailed compendium summarizing the sources and variables used is available in the Appendix.

Before proceeding with the estimation of the MIMIC, we need to devise a set of possible causes and indicators for our model. The pool of variables believed to have direct or indirect impacts on informality in the literature is varied. However, the limited availability of Mexican data for the period of interest has strongly constrained our choices.

\section{Causes}

\footnotetext{
${ }^{11}$ For more details on necesary conditions see Bollen (1989) and Dell'Anno et al. (2007).

${ }^{12}$ This is one of the most controversial points when using the MIMIC model in order to estimate the informal economy. See Breusch (2005) and Dell'Anno and Schneider (2006).
} 
1. Taxes: An excessive burden is believed to incentive first of all general evasion. Second, and in a minor scale, it also pushes economic agents into illegal labor, working as a deterrence for potential entrepreneurs wishing to enter the official markets, and hence encouraging them to establish within the informal sector. Therefore, taxes are believed to have a direct positive impact on the informal economy: the higher the burden the bigger the informality growth. This variable is usually proxy using the ratio between tax revenues and GDP, and when possible decomposed into direct and indirect tax rates.

2. Inflation: This can be seen as a proxy for macro stability. The Mexican economy, as well as the rest of Latin America, suffered from high inflation rates during the 1980's, destabilizing the credit sector, wiping out small businesses and fostering black markets. Consequently, higher inflation rates are expected to affect positively informality.

3. Salaries: The salaries in Mexico have been fixed for years. Even today, their levels, especially for the manufacturing sector, grow at rates well below the inflation, thus allowing established companies to take advantage of unskilled workers, and incentivating the latter to search better opportunities and sources of income within informality. An increase in official salaries should affect negatively the informal economy.

In Figure 2 we can appreciate the loss in real terms that salaries have suffered in Mexico in the last decades. It is important to point out that we are referring to minimum wages, fixed each year by the government.

Figure 2. Mexican Real Minimum Wages

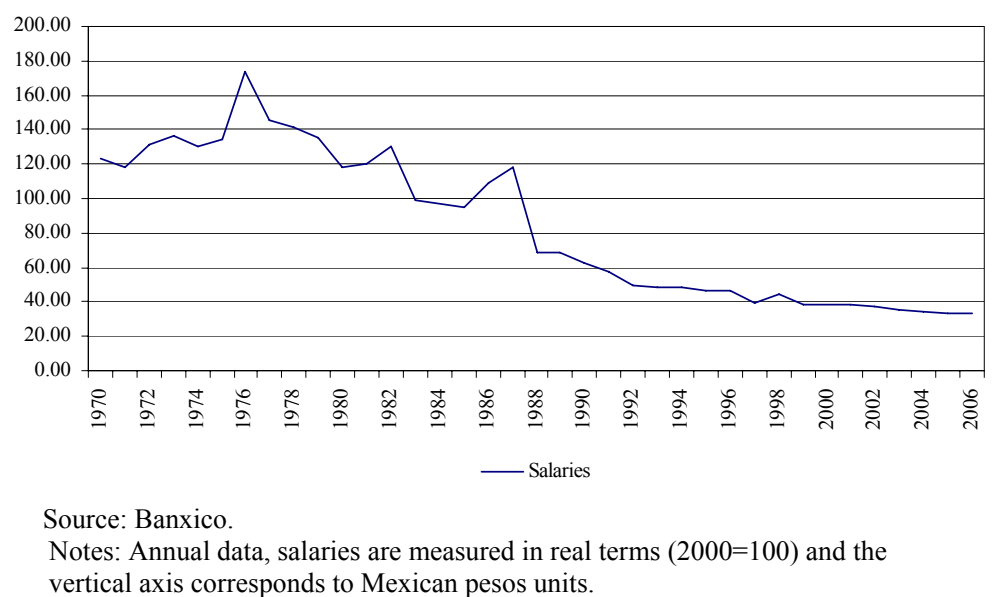

4. Government: The size of the public sector usually serves as an indicator of efficiency and bureaucracy. Excessive regulation is believed to be a key factor encouraging informal activities $^{13}$ as well as delaying procedures and services, and laying the bases for government corruption. In this study, we use as a proxy for this variable the ratio of government consumption to GDP.

\footnotetext{
${ }^{13}$ See Johnson et al. (1997), Aigner et al. (1988).
} 
5. Unemployment: The effect of this variable is still unclear. On one hand, an increase in unemployment should encourage dismissed workers to try fortune in the informal markets. However, on the other hand, high rates of unemployment are usually a sign for a generalized adverse economic situation, which should or could affect equally both sectors, the formal and informal.

\section{$\underline{\text { Indicators }}$}

1. Currency: One of the basic assumptions in most informal sector studies is that a significant part of informal transactions take place using solely cash, so that they can avoid to be detected. Hence, the use of the amount of money that is in circulation should be a fair indicator of increases or decreases in unrecorded transactions. This variable is usually approximated using different currency ratios that include several measures of money, i.e. currency outside the banks, M1, M2, M3, M4, etc. Dell'Anno and Solomon (2007) use M1/M2 for a specific study measuring the U.S. underground economy, while Dell'Anno et al. (2007) use M1/M3 for the analysis of some Mediterranean countries. On the other hand, Giles and Tedds (2002) and Bajada and Schneider (2005) use the growth of currency in circulation outside of banks, since they consider it a much more reliable indicator than any currency ratio. So, in this paper, we will use real currency in hands of the public, and increases in the latent variable $\eta$ (informal economy) are expected to have a positive impact on our currency variable.

2. Real GDP: In general when estimating the informal sector, we need a reference variable. As we already discussed in the previous section, in order to estimate the MIMIC model we need to set a scale. In most studies dealing with the underground economy, the chosen variable used to fix a scale is GDP, although in some cases we can find alternative variables, such as real currency per capita (see Bajada and Schneider, 2005). This brings us to a first dilemma: which variable do we need to fix (normalize)?, and which sign should we assign to the normalized variable? In theory, informality should have a direct impact on GDP, and so this can be easily agreed upon. However, as we have been arguing, the direction of this impact is unclear. Indeed, the work by Alanon and Gomez-Antonio (2005), among others, finds a positive relationship, while Dell'Anno ${ }^{14}$ and Schneider (2003), and Vuletin (2006) find a negative relationship. In this paper, we will use real GDP as the scale variable, and we will set the direction of the effect using Dell'Anno et al. (2007) strategy, which consists in changing the sign of the scale coefficient $(+/-)$. By doing this we will affect the signs of structural parameters $(\gamma)$ but not their absolute values, which will remain the same. Now, using economic theory we can verify if the estimated signs are consistent with economic theory, and therefore choose the best model.

\footnotetext{
${ }^{14}$ To our knowledge, Dell'Anno (2003) was the first one to set negatively the normalized GDP.
} 
Below we present the graphical representation of the most general model to be used for empirical estimation.

Figure 3. MIMIC 5-1-2

Causes

Latent Variable

Indicators

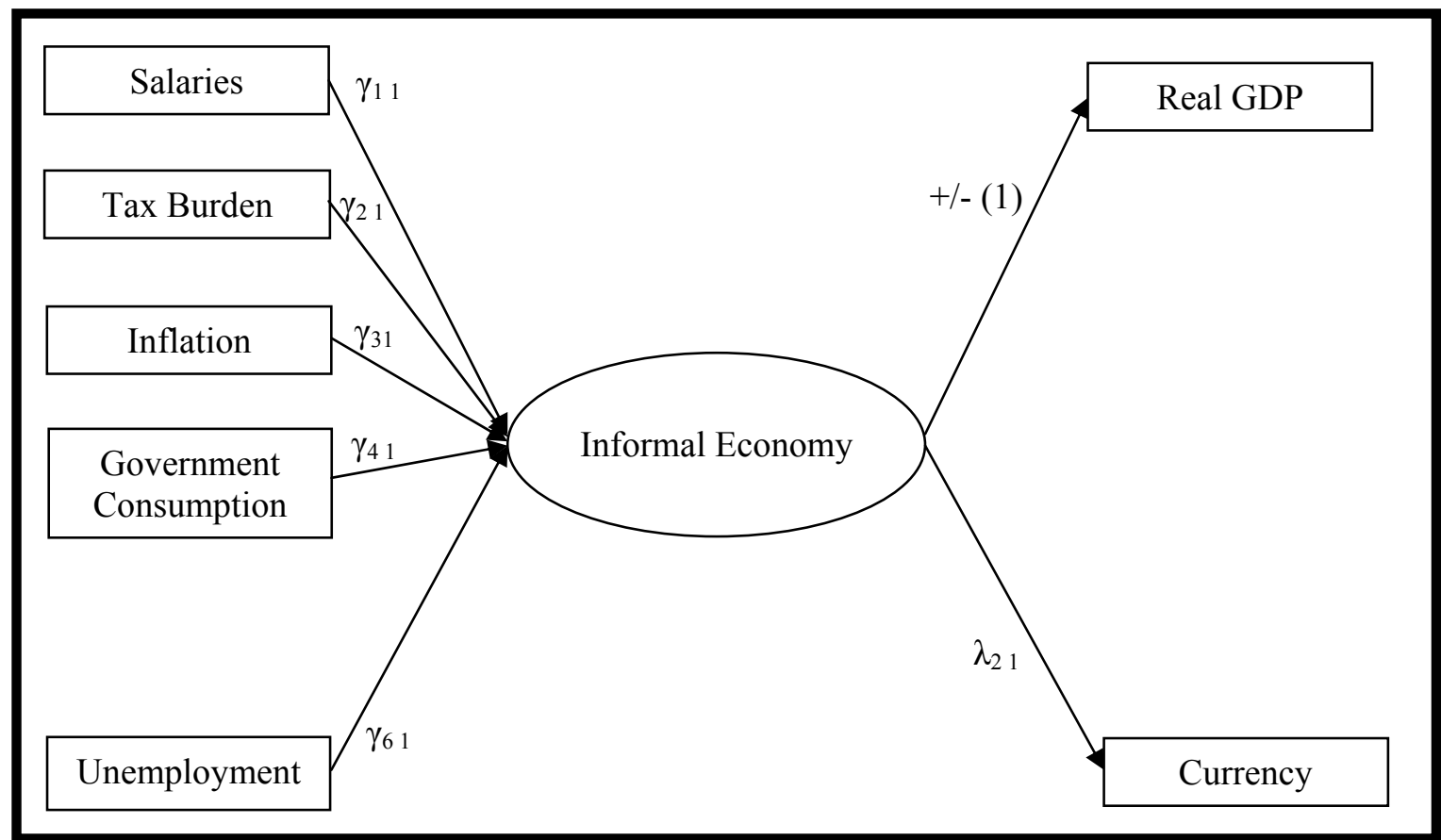

\section{MIMIC Estimation Results}

Having in mind the previous model (MIMIC 5-1-2), it is worth to stress that, as the sample size grows and data are normally distributed, coefficient instability will disappear asymptotically. So, the size of the sample and its nature have a direct impact on the reliability of the final estimation. Unfortunately, in our case we are data constrained and can rely only on annual data for the past three decades. However, according to Stevens (1996), although having more is advisable, 35 observations per variable could be enough for our purposes.

In Table 1 we summarize our MIMIC regressions. Columns refer to the different models used, where the first number identifies the number of cause variables used, while the second number denotes the number of latent variables and the last digit enumerates the indicator variables. For example, columns (5-1-2) uses 5 causes (i.e. inflation, salaries, taxes, unemployment and government consumption), one latent variable (in our case the informal sector) and two indicator variables (GDP and currency). 
Table 1. Structural Equation Modeling

MIMIC regressions

\begin{tabular}{|c|c|c|c|c|c|c|c|}
\hline \multirow{2}{*}{ Variables } & \multicolumn{7}{|c|}{ Models } \\
\hline & $(5-1-2)$ & $(4-1-2)$ & $(4-1-2)$ & $(5-1-2)$ & $(4-1-2)$ & $(3-1-2)$ & $(3-1-2)$ \\
\hline \multicolumn{8}{|l|}{ Indicators } \\
\hline \multirow[t]{2}{*}{ GDP } & 1.00 & 1.00 & 1.00 & $1.56^{*}$ & $1.56^{*}$ & $1.79^{*}$ & 1.00 \\
\hline & & & & $(0.16)$ & $(0.16)$ & $(0.23)$ & \\
\hline \multirow[t]{2}{*}{$\mathrm{C}$} & $0.64 *$ & $0.57^{*}$ & $0.64 *$ & 1.00 & 1.00 & 1.00 & $0.56^{*}$ \\
\hline & $(0.065)$ & $(0.070)$ & $(0.065)$ & & & & $(0.072)$ \\
\hline \multicolumn{8}{|l|}{ Causes } \\
\hline \multirow[t]{2}{*}{ Inflation } & $0.003^{*}$ & $0.003 *$ & $0.003 *$ & $0.002 *$ & $0.002 *$ & $0.001 *$ & $0.003 *$ \\
\hline & $(.00042)$ & $(0.00050)$ & $(0.00041)$ & $(0.00034)$ & $(0.00034)$ & $(0.00036)$ & $(0.00047)$ \\
\hline \multirow[t]{2}{*}{ Salaries } & $-0.410^{*}$ & $-0.520 *$ & $-0.410^{*}$ & $-0.260 *$ & $-0.260 *$ & $-0.270^{*}$ & $-0.490^{*}$ \\
\hline & $(0.044)$ & $(0.049)$ & $(0.035)$ & $(0.042)$ & $(0.038)$ & $(0.055)$ & $(0.048)$ \\
\hline \multirow[t]{2}{*}{ Tax } & 0.002 & $0.032 *$ & & 0.001 & & & \\
\hline & $(0.019)$ & $(0.018)$ & & $(0.012)$ & & & \\
\hline \multirow[t]{2}{*}{ Unemployment } & $-0.054 *$ & $-0.041^{*}$ & $-0.055^{*}$ & $-0.035^{*}$ & $-0.035^{*}$ & $-0.027^{*}$ & $-0.049^{*}$ \\
\hline & $(0.012)$ & $(0.013)$ & $(0.010)$ & $(0.0085)$ & $(0.0077)$ & $(0.0082)$ & $(0.012)$ \\
\hline \multirow[t]{2}{*}{ Gov } & $0.076^{*}$ & & $0.076^{*}$ & $0.049^{*}$ & $0.049^{*}$ & & \\
\hline & $(0.013)$ & & $(0.010)$ & $(0.010)$ & $(0.0088)$ & & \\
\hline Standardized RMR & 0.095 & 0.095 & 0.090 & 0,10 & 0,09 & 0,06 & 0,06 \\
\hline Goodness of Fit Index (GFI) & 0,84 & 0,91 & 0,81 & 0,84 & 0,81 & 0,96 & 0,96 \\
\hline Parsimony Goodness of Fit Index (PGFI) & 0,12 & 0,13 & 0,12 & 0,12 & 0,12 & 0,13 & 0,13 \\
\hline
\end{tabular}

Note: The Lisrel regressions were estimated using annual data starting in 1970 till 2006. Standard errors in parenthesis.

* Indicates significance at the 5 percent level.

Table 1 is divided into three sections. The first block corresponds to the indicator variables, the second one to the causes and the third part groups the fitness of the models.

Along with individual significance, in the third block we report the overall fitness of the different models. First, we report the standardized root mean square residual (RMR), where small values are preferred. On the other hand, we present the goodness of fit index (GFI) and the parsimony goodness of fit index (PGFI): the bigger the values the better the fit of the model ${ }^{15}$.

As mentioned before, in order to estimate our MIMIC models we need to fix a scale variable ${ }^{16}$. So, in this case, we run regressions fixing GDP and alternatively Currency, adding and subtracting the possible causal variables. From the regressions we can appreciate that the models used are quite stable and their GFIs fluctuate around 0.9. Furthermore, signs are as expected. Inflation, taxes and government consumption have a positive impact on the size of the informal sector: an increase in these variables will push more agents into the informal sector.On the other hand, official salaries have a negative effect on the size of the informal economy: the higher and more competitive the national salaries the less incentives to risk going to the informal sector. So, government policy on

\footnotetext{
${ }^{15}$ It is important to point out that the goodness of fit reported in Table 1 are not exhaustive of all the wide range of indices available in the LISREL program (http://www.ssicentral.com/index.html). Nevertheless, we decided to report the ones that in our opinion were the most representative. For interested readers, a clear assesment of goodness of fit indices available can be found in Diamantopoulos and Siguaw (2000).

${ }^{16}$ The scale variable is essential to estimate the rest of the parameters, since they will be a function of the former.
} 
determining high minimum wages could have an overall strong effect deterring agents from going to the informal sector.

Surprisingly, unemployment seems to have a negative effect on the size of the informal sector. Although this is in line with previous regional studies (see Hametner and Schneider, 2007), the result is intriguing and its interpretation should be taken with caution.

Nevertheless, in the Mexican case, it seems that national economic shocks that affect the formal sector creating for example rises in unemployment hit in a parallel way the informal markets. In other words, both markets are exposed, probably at different degrees, to overall external economic shocks.

\section{Modeling the Informal Economy.}

One of the characteristics of the MIMIC model is that it will only provide a group of estimated coefficients that can be used to create an index. So, the researcher is obliged to use a benchmark or calibration method to convert the resulting index into cardinal values that can be used to get a time series of the informal sector. This is without doubt a limitation to this type of modeling, especially due to the fact that we are assigning a specific meaning and interpretation to our latent variable, which is open to subjectiveness and therefore is an object of concerns and criticism (see Breusch, 2005, and Dell'Anno, 2003).

In this study, we follow Giles and Tedds (2002) benchmark method ${ }^{17}$ and proceed to calibrate our model as follows:

$$
\left(\frac{\eta}{Y}\right)_{t}^{\text {final }}=\mu\left(\frac{\eta}{Y}\right)_{t}^{\text {ordinal }}
$$

where $\left(\frac{\eta}{Y}\right)_{t}^{\text {ordinal }}$ corresponds to the value of the index of our shadow economy as a ratio of the official GDP (Y) at time $t$, which is calculated using equation (2), and $\mu$ is a constant and is given by the following expression:

$$
\mu=\frac{\left(\frac{\eta}{Y}\right)_{\bar{T}}^{*}}{\left(\frac{\eta}{Y}\right)_{\bar{T}}^{\text {ordinal }}}
$$

In equation (8), $\left(\frac{\eta}{Y}\right)_{\bar{T}}^{*}$ is the value of the informal sector taken from an exogenous source, usually obtained through other methodologies or sources. In our case, we used Vuletin (2006) and the results obtained in Brambila-Macias (2008) to get an average of the informal sector at time $\bar{T}$ (i.e. 2006). So, using equations (7) and (8), we can get an estimate of the Mexican informal sector at a

\footnotetext{
${ }^{17}$ Until now, there is no consensus in the economic literature regarding which benchmark procedure is the most reliable. Some alternative procedures can be found in Dell'Anno and Schneider (2003) and Bajada and Schneider (2005).
} 
certain base period that should be equal to the exogenous source, allowing us to compute the rest of the time series accordingly.

In Figure 4, we illustrate the evolution of the Mexican informal sector in the last three decades and compare it to another time series that was computed by Brambila-Macias (2008) using the Currency Demand Approach (CDA).

Figure 4. Formal vs. Informal GDP

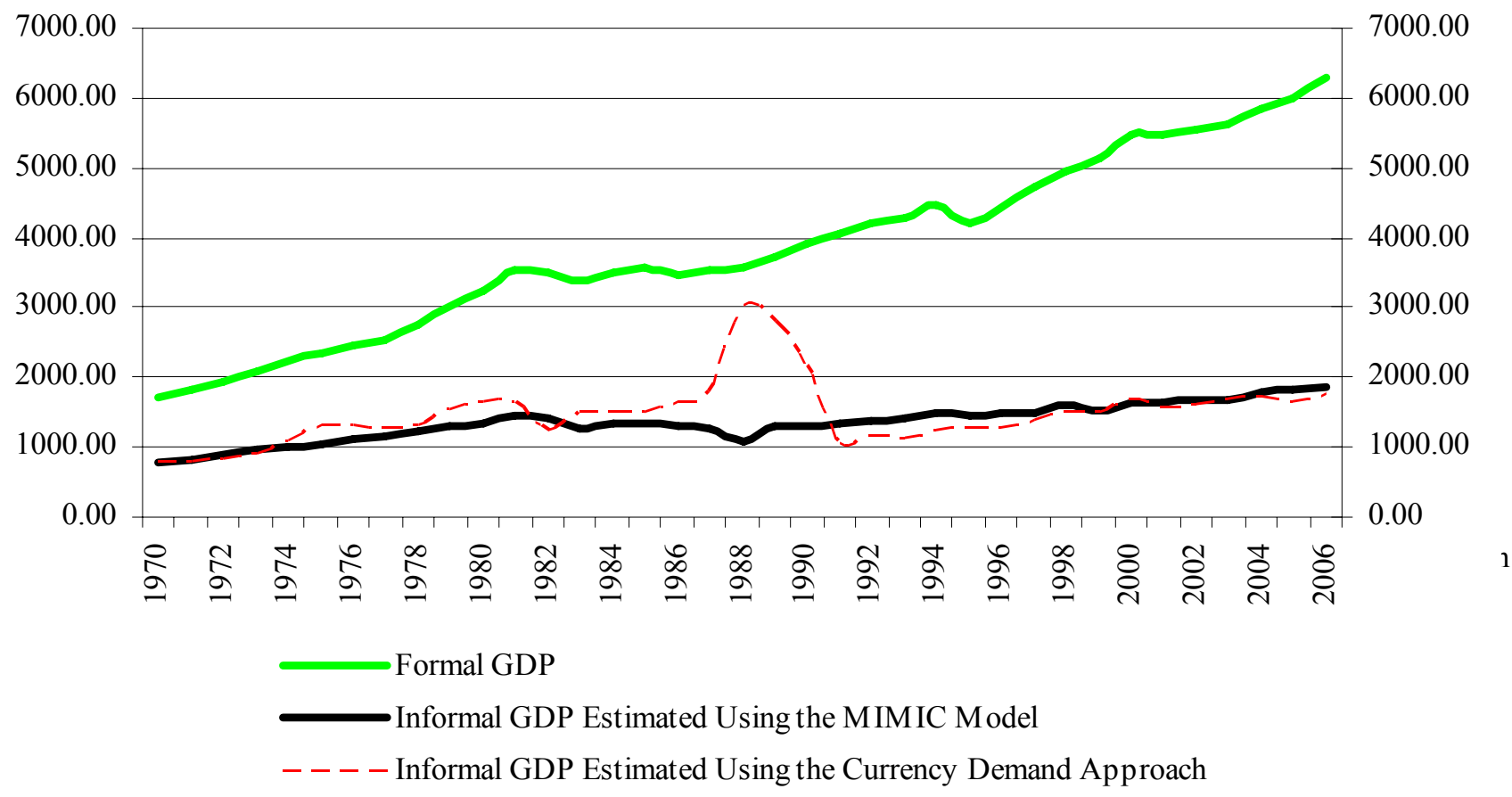

Note: Units in Billions of Mexican Pesos

Differently from other specific country studies, in the present paper our MIMIC estimates fairly overlaps the series obtained through the currency demand approach, with the exception of the period 1988-1991, where the MIMIC series remains stable while the CDA estimates present a hump.

This divergence could be due, on one hand, to the nature of the CDA, which is a monetary method and so it is quite sensible to inflation, and the late 1980's were a period of hyperinflation in Mexico and in the rest of Latin America. On the other hand, while both series were estimated using taxes, currency outside banks in the hands of the public and observable GDP, they differ on the other variables used, i.e. remittances and interest rates for the CDA, and unemployment and salaries for the MIMIC.

Nevertheless, both series confirm the increase of the informal sector in the early 1970's up to a level around 40 percent of GDP and its decrease and stabilization around 30 percent of GDP during the 1990's and early 2000's. 


\section{Final Remarks.}

Informality plays a crucial role in the global economy and certainly has a direct impact on national economic growth. On one hand, the existence of informality has taken off some pressure on poor countries $^{18}$, providing much needed sources of income for many people, while, on the other hand, it has deprived governments from potential funds in the form of taxes that could be used, if managed appropriately, into channelling productive investment. To what extent one of these two effects can offset the other is still an open question, although it is certainly clear that incorporating the informal sector into the formal markets may have a positive impact on the economy.

In this paper, we used a special case of structural equation modeling in order to get a proxy of the size of the informal sector in Mexico. Besides estimating the size of informality, the other aim of this study was to provide researchers with a reliable time series that can be used in further analysis of the phenomenon and its possible interactions with other important aspects of economic growth.

From our results we can track the evolution of the Mexican informal sector during the past three decades. Our results indicate the stabilization of informality at levels around 30-40 percent of GDP since about the late 1980 's, identifying as main potential causes taxation, low salaries and excessive regulation (proxied by government consumption). All these causes could be corrected using an adequate governance framework that, giving the appropriate incentives, could redirect informal flows from spurious consumption to productive investment in the regular economy.

For future research, we believe it would be interesting, whenever the data are available, to conduct an analysis of the informal sector at a micro level, in order to help to determine with more precision economic policies that could deal with this phenomenon.

\footnotetext{
${ }^{18}$ According to the IADB (2006), in a regional report assessing the informal sector in Jamaica, the reduction on poverty rates (44 percent in 1991 to 17 percent in 2001) could be explained to some extent by the robust performance of informal sector.
} 


\section{Appendix}

\section{DATA}

\begin{tabular}{|c|c|c|}
\hline Variable & $\begin{array}{l}\text { Description } \\
\end{array}$ & Sources \\
\hline$C$ & $\begin{array}{l}\text { Currency over GDP deflator } \\
\text { 1970-2006 annual data, national } \\
\text { currency. }\end{array}$ & $\begin{array}{l}\text { International Finance Statistics } \\
\text { (IMF) and Banxico }\end{array}$ \\
\hline$Y$ & $\begin{array}{c}\text { Real GDP }(2000=100) \\
1970-2006 \text { annual data, } \\
\text { national currency }\end{array}$ & $\begin{array}{l}\text { International Finance Statistics } \\
\text { (IMF) and Banxico }\end{array}$ \\
\hline Salaries & $\begin{array}{c}\text { Real minimum wages } \\
\text { 1970-2006 annual data } \\
\text { national currency }\end{array}$ & $\begin{array}{c}\text { Mexican Central Bank database: } \\
\text { Banxico }\end{array}$ \\
\hline Unemployment & $\begin{array}{c}\text { Unemployment rate } \\
\text { 1970, 1975, 1980-2006 } \\
\text { Annual rates }\end{array}$ & $\begin{array}{l}\text { OECD statistics database and } \\
\text { INEGI. } \\
\text { Note: The series is incomplete } \\
\text { and was extended using } \\
\text { economic active population } \\
\text { growth rates. }\end{array}$ \\
\hline Gov & $\begin{array}{c}\text { Government consumption } \\
\text { normalized by GDP } \\
1970-2006\end{array}$ & $\begin{array}{l}\text { International Finance Statistics } \\
\text { (IMF) and Banxico }\end{array}$ \\
\hline Inflation & $\begin{array}{l}\text { Annual inflation rates } \\
1970-2006, \text { CPI change }\end{array}$ & $\begin{array}{c}\text { International Finance Statistics } \\
\text { (IMF) }\end{array}$ \\
\hline $\operatorname{Tax}$ & $\begin{array}{c}\text { Tax revenues over GDP } \\
1970-2006\end{array}$ & $\begin{array}{l}\text { This series is partially } \\
\text { available online, data before } \\
\text { the late 1980's is available } \\
\text { only on paper records. The } \\
\text { series used in this paper comes } \\
\text { mainly from the Mexican } \\
\text { Central Bank online database } \\
\text { (www.banxico.com) } \\
\text { Alternative sources are: The } \\
\text { Mexican Secretariat for Public } \\
\text { Finance (SHCP), The National } \\
\text { Statistics Institute (INEGI) and } \\
\text { the Mexican Senate Economic } \\
\text { Affairs Center. }\end{array}$ \\
\hline
\end{tabular}


INEGI Survey

\begin{tabular}{c|c}
\hline Year & $\begin{array}{c}\text { Informal } \\
\text { Sector }\end{array}$ \\
\hline \hline 2000 & 26.96 \\
2001 & 27.52 \\
2002 & 28.24 \\
2003 & 28.81 \\
2004 & 28.76 \\
2005 & 28.13 \\
2006 & 27.20 \\
\hline \multicolumn{2}{l}{ Source: INEGI, Mexico. } \\
Note: Annual Averages
\end{tabular}




\section{References}

Aigner, D. J., F. Schneider, and G. Damayanti (1988), "Me and my shadow: estimating the size of the U.S. hidden economy from time series data", in W. A. Barnett et al. (eds.), Dynamic Econometric Modelling: Proceedings of the Third International Symposium in Economic Theory and Econometrics. Cambridge University Press, Cambridge, pp. 297- 334.

Alañón, A., and M. Gómez-Antonio (2005), "Estimating the Size of the Shadow Economy in Spain: A Structural Model with Latent Variables", Applied Economics, 37(9), pp. 1011-1025.

Bajada, C., and F. Schneider (2005), "The Shadow Economies of the Asia-Pacific", Pacific Economic Review, 10(3), pp. 379-401.

Bollen, K. A. (1989), "Structural equations with latent variables”. John Wiley \& Sons, New York.

Brambila-Macias, J. (2008) "The Dynamics of Parallel Economies. Measuring the Informal Sector in Mexico", MPRA Paper No. 8400.

Breusch, T. (2005), "Estimating the Underground Economy using the MIMIC Models", The Australian National University.

Dell'Anno, R. (2003), "Estimating the Shadow Economy in Italy: a Structural Equation Approach," Department of Economics, Working Papers 2003-7, Department of Economics, University of Aarhus, Denmark.

Dell'Anno, R., and F. Schneider (2003), "The Shadow Economy of Italy and other OECD Countries: What do we know?, Journal of Public Finance and Public Choice, XXI(2-3), pp. $97-120$.

Dell'Anno, R., and F. Schneider ( 2006), "Estimating the underground economy by using MIMIC models: A Response to T. Breusch's critique" Economics working papers 2006-07, Department of Economics, Johannes Kepler University Linz, Austria.

Dell'Anno,, R., and O.H. Solomon (2007), "Shadow economy and unemployment rate in USA: is there a structural relationship? An empirical analysis", Applied Economics, pp. 1-19.

Dell'Anno, R., M. Gomez-Antonio, and A. Pardo. (2007), "The Shadow economy in three Mediterranean countries: France, Spain and Greece. A MIMIC approach” Empirical Economics, 33, pp. 51-84.

Diamantopoulos, A. and J. Siguaw (2000), “Introducing LISREL”, SAGE Publications, London, UK.

Feige, E. (1979), "How big is the irregular economy?”, Challenge, 22, pp. 5-13.

Frey, B., and H. Weck-Hanneman (1984), "The Hidden Economy as an Unobservable variable". European Economic Review, 26(1), pp. 33-53.

Garcia-Verdu, R. (2007), "The Informal Sector: What Is It, Why Do We Care, and How Do We Measure It?", mimeo.

Giles, D., and L. Tedds (2002), "Taxes and The Canadian Underground Economy”, Canadian Tax Foundation Toronto, Paper n. 106, Canada.

Goldberger, A. S. (1972), "Structural Equation Methods in the Social Sciences", Econometrica, 40, pp. 979-1001. 
Hametner, B., and F. Schneider (2007), "The shadow economy in Colombia: size and effects on economic growth" Working Paper 2007-03, Department of Economics, Johannes Kepler University Linz, Austria.

Hart, K. (1973), "Informal Income Opportunities and Urban Employment in Ghana." Journal of Modern African Studies, 11, pp. 61-89.

Hart, K. (1990), "The Idea of Economy: Six Modern Dissenters" in: R. Friedland and A. F. Robertson (eds.), Beyond the Marketplace, Rethinking Economy and Society, New York, Aldine de Gruyter, pp. 13760

IADB (2006), “The Informal Sector in Jamaica”, Economic and Sector Study Series RE3-06-010, Washington DC.

ILO (1999), "Panorama Laboral 99, Informa 6", International Labour Organisation, Lima.

Johnson, S., D. Kaufmann, and A. Shleifer (1997), "The Unofficial Economy in Transition", Brooking Papers of Economic Activity, 0:2, pp. 159-221

Jöreskog, K., and A.S. Goldberger (1975), “Estimation of a model with multiple indicators and multiple causes of a single latent variable", Journal of the American Statistical Association, 70, pp. 631-639.

Kaufmann, D., and A. Kaliberda (1996), "Integrating the unofficial economy into the dynamics of the post-socialist economies: A framework of analysis and evidence", in B. Kaminski (ed.), Economic transition in Russia and the new states of Eurasia. Armont, New York: M.E. Sharpe, Inc.

Loayza, N. (1997), "The economics of the informal sector: a simple model and some empirical evidence from Latin America", World Bank Policy Research Working Paper, WPS 1727, The World Bank, Washington, DC.

OECD (2002), "Measuring the Non-Observed Economy - A Handbook", Statistics Directorate, Paris, France.

Roubaud, F.(1995), "La Economia Informal en Mexico. De la esfera domestica a la dinamica macroeconomica", Fondo de Cultura Economica, Mexico.

Schneider, F. and D. Enste (2000), "Shadow economies: size, causes and consequences", Journal of Economic Literature, American Economic Association, 38, pp. 77-114.

Schneider, F. (2002), "Size and measurement of the informal economy in 110 countries around the world", Rapid Response Unit, The World Bank, Washington, DC.

Stevens, J. (1996), “Applied multivariate statistics for the social sciences”. Lawrence Erlbaum Associates, Inc., USA.

Tanzi, V. (1983), "The underground economy in the United States: Annual estimates, 1930-1980", IMF Staff Papers, 33, International Monetary Fund, pp. 283-305.

Vuletin, G. (2006), "What is the size of the Pie? Measuring the Informal Economy in Latin American and the Caribbean." Forthcoming IMF Working Paper, International Monetary Fund, Washington, DC. 